\title{
The Core Molecular Machinery Used for Engulfment of Apoptotic Cells Regulates the JNK Pathway Mediating Axon Regeneration in Caenorhabditis elegans
}

\author{
Strahil Iv. Pastuhov, Kota Fujiki, Anna Tsuge, Kazuma Asai, Sho Ishikawa, Kazuya Hirose, Kunihiro Matsumoto, \\ and Naoki Hisamoto \\ Division of Biological Science, Graduate School of Science, Nagoya University, Chikusa-ku, Nagoya 464-8602, Japan
}

\begin{abstract}
The mechanisms that govern the ability of specific neurons to regenerate their axons after injury are not well understood. In Caenorhabditis elegans, the initiation of axon regeneration is positively regulated by the JNK-MAPK pathway. In this study, we identify two components functioning upstream of the JNK pathway: the Ste20-related protein kinase MAX-2 and the Rac-type GTPase CED-10. CED-10, when bound by GTP, interacts with MAX-2 and functions as its upstream regulator in axon regeneration. CED-10, in turn, is activated by axon injury via signals initiated from the integrin $\alpha$-subunit INA- 1 and the nonreceptor tyrosine kinase SRC-1 and transmitted via the signaling module CED-2/CrkII-CED-5/Dock180-CED-12/ELMO. This module is also known to regulate the engulfment of apoptotic cells during development. Our findings thus reveal that the molecular machinery used for engulfment of apoptotic cells also promotes axon regeneration through activation of the JNK pathway.
\end{abstract}

Key words: axon regeneration; C. elegans; Rac; signal transduction

\section{Significance Statement}

The molecular mechanisms of axon regeneration after injury remain poorly understood. In Caenorhabditis elegans, the initiation of axon regeneration is positively regulated by the JNK-MAPK pathway. In this study, we show that integrin, Rac-GTPase, and several other molecules, all of which are known to regulate engulfment of apoptotic cells during development, also regulate axon regeneration. This signaling module activates the JNK-MAPK cascade via MAX-2, a PAK-like protein kinase that binds Rac. Our findings thus reveal that the molecular machinery used for engulfment of apoptotic cells also promotes axon regeneration through activation of the JNK pathway.

\section{Introduction}

A fundamental and conserved property of neurons is their ability to regenerate their axons after injury, an ability that is modulated by interactions between the intrinsic axon growth machinery and the local extracellular environment. In adult mammals, the PNS

Received Feb. 9, 2016; revised June 27, 2016; accepted July 25, 2016.

Author contributions: S.I.P., K.F., K.M., and N.H. designed research; S.I.P., K.F., A.T., K.A., K.H., S.I., and N.H. performed research; S.I.P., K.M., and N.H. analyzed data; S.I.P., K.M., and N.H. wrote the paper.

This work was supported by the Ministry of Education, Culture and Science of Japan (K.M.); MEXT (Grant-in-Aid for Scientific Research on Innovative Areas "Homeostatic regulation by various types of cell death," $15 \mathrm{H} 01375$ to N.H.); the Mitsubishi Foundation (K.M.); the Naito Foundation (N.H.); the Daiko Foundation (N.H.); and the Astellas Foundation (N.H.). S.P. is an overseas researcher under a postdoctoral fellowship from the Japan Society for the Promotion of Science. We thank M. Bastiani and P. Nix for providing information and for helpful discussion and K. Kaibuchi of the Caenorhabditis Genetic Center and C. elegans Knockout Consortium for materials.

The authors declare no competing financial interests.

Correspondence should be addressed to either Kunihiro Matsumoto or Naoki Hisamoto, Division of Biological Science, Graduate School of Science, Nagoya University, Chikusa-ku, Nagoya 464-8602, Japan. E-mail: g44177a@nucc.cc.nagoya-u.ac.jp or i45556a@cc.nagoya-u.ac.jp.

DOI:10.1523/JNEUROSCI.0453-16.2016

Copyright $\odot 2016$ the authors $\quad 0270-6474 / 16 / 369710-12 \$ 15.00 / 0$ regenerates relatively efficiently, whereas CNS axons regenerate poorly (Chen et al., 2007). This distinction between central and peripheral axon regeneration has been attributed to the combined effects of extrinsic signals provided by the inhibitory glial environment and intrinsic growth capabilities (Case and TessierLavigne, 2005). Because intrinsic regeneration signals can influence regenerative success, they represent potential therapeutic targets to enhance regeneration. However, our understanding of the intrinsic signaling pathways that promote regeneration in the adult nervous system remains limited.

The nematode Caenorhabditis elegans has recently emerged as an attractive model with which to dissect the mechanisms of axon regeneration (Yanik et al., 2004; Hammarlund et al., 2009). Its amenability to genetic analysis makes possible the discovery and elucidation of novel signaling pathways involved in regeneration. Indeed, genetic screens have identified many such genes and pathways, including those specifically required for adult axon regrowth (Chen et al., 2011; Nix et al., 2014). Recent genetic studies have shown that, in C. elegans, the JNK-MAPK pathway 
functions as a key intrinsic regulator of the initiation of regeneration and may be involved in the sensing of axonal damage (Nix et al., 2011; Li et al., 2012, 2015). The MAPK signaling pathways respond to a variety of extracellular stimuli, generating a diverse array of physiological responses within the cell (Ichijo et al., 1997; Ninomiya-Tsuji et al., 1999), and thus are involved in the regulation of cell proliferation, differentiation, regeneration, stress response, and apoptosis. The C. elegans JNK pathway is composed of the components MLK-1 MAPKKK, MEK-1 MAPKK, and KGB-1-JNK. In a typical MAPK cascade, activation of the upstream MAPKKK is a critical control point for signal specificity and amplification (English et al., 1999). In the case of axon regeneration, we showed recently that TPA-1, a C. elegans protein kinase C (PKC), functions upstream of MLK-1 in the KGB-1 pathway regulating regeneration (Pastuhov et al., 2012). TPA-1 phosphorylates MLK-1 on Ser-355 of the kinase domain activation loop, leading to its activation.

The C. elegans KGB-1-JNK pathway also regulates the stress response to heavy metals (Mizuno et al., 2004; Fujiki et al., 2010). In this pathway, the protein kinase MAX-2, related to yeast Ste20, also activates MLK-1 through direct phosphorylation of Ser-355. Furthermore, the Rac-type GTPase MIG-2 functions upstream of MAX-2 in the KGB-1-mediated stress response pathway. In this study, we show that MAX-2 and another Rac-type GTPase, CED10 , regulate axon regeneration upstream of MLK-1. We also demonstrate that the integrin $\alpha$-subunit INA- 1 activates the JNK pathway through the signaling complex CED-2-CED-5-CED12 , thereby activating axon regeneration. The INA-1-CED-10 signaling pathway was shown previously to regulate the engulfment of apoptotic cells during development (Hsu and $\mathrm{Wu}, 2010$ ). Therefore, the conserved INA-1-CED-10 signaling unit used for engulfment of apoptotic cells is also used to promote axon regeneration.

\section{Materials and Methods}

C. elegans strains. The C. elegans strains used in this study are listed in Table 1. All strains were maintained on nematode growth medium plates and fed with bacteria of the OP50 strain, as described previously (Brenner, 1974).

Plasmids. Punc-25::ced-10(G12V) and Punc-25::ced-10(T17N) were generated by cloning the $c e d-10$ cDNA isolated from a cDNA library (Kawasaki et al., 1999), mutagenizing it to generate the GTP and GDP-bound form, respectively, and inserting the resulting constructs into the pSC325 vector. Punc-25::ina-1 and Punc-25::ina-1::gfp were made by cloning the ina-1 cDNA isolated from a cDNA library (Kawasaki et al., 1999) and inserting it into the pSC325 vector. For Punc-25::ina-1::gfp, the last coding codon of ina- 1 was ligated in frame with the $g f p$ coding sequence obtained from the pPD95.75 vector. Punc-25:: max-2 was made by inserting max-2 cDNA into the pSC325 vector. Punc-25::mlk-1 (S355E) and Pmyo-2::dsredmonomer were described previously (Arimoto et al., 2011; Pastuhov et al., 2012). The GAL4 DBD-CED-10(G12V) and GAL4 DBD-CED-10(T17N) plasmids were generous gifts from Dr. Kozo Kaibuchi. The GAL4 AD-MAX-2 plasmid has been described previously (Fujiki et al., 2010). To make the GAL4 AD-MAX2(CRIB) plasmid, the DNA region corresponding to the 41-91 aa of MAX-2 protein was amplified by PCR and subsequently subcloned into the PACTII vector.

Transgenic animals. Transgenic C. elegans animals were obtained by a standard microinjection method (Mello et al., 1991). Pmyo-2::dsredmonomer (25 $\mathrm{ng} / \mu \mathrm{l})$, Punc-25::ced-10(G12V) (25 ng/ $\mu \mathrm{l})$, Punc-25::ced-10(T17N) $(25 \mathrm{ng} / \mu \mathrm{l})$,

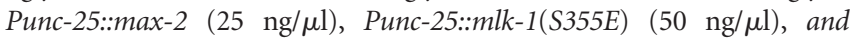
Punc-25::ina-1::gfp plasmids were used in kmEx466 [Punc-25::ced-10(G12V) + Pmyo-2::dsredmonomer], kmEx467 [Punc-25::ced-10(T17N) + Pmyo-2:: dsredmonomer], kmEx468 [Punc-25::max-2 + Pmyo-2::dsredmonomer], kmEx469 [Punc-25::mlk-1(S355E) + Pmyo-2::dsredmonomer], and kmEx472 [Punc-25::ina-1::gfp + Pmyo-2::dsredmonomer]. A fosmid fragment containing
Table 1. C. elegans strains used in this study

\begin{tabular}{|c|c|}
\hline Strain & Genotype \\
\hline $\mathrm{N} 2$ & Wild-type \\
\hline KU21 & kgb-1(km21) IV \\
\hline KU405 & $\max -2(n v 162) / I$ \\
\hline KU406 & $\max -2($ nv162) II;tpa-1(k501) IV \\
\hline KU461 & juls76 II;tpa-1(k501) IV \\
\hline KU462 & juls76;mlk-1(km19) V \\
\hline KU501 & juls76 II \\
\hline KU708 & juls76 max-2(nv162) II \\
\hline KU709 & juls76 max-2(nv162) Il;tpa-1(k501) IV \\
\hline KU710 & $\begin{array}{l}\text { juls76 max-2(nv162) II;tpa-1(k501) IV;Ex[Punc-25::mlk-1(S355E); } \\
\text { Pmyo-2::dsredmonomer] }\end{array}$ \\
\hline KU711 & juls76 II;ced-10(n3246) IV \\
\hline KU712 & juls76 max-2(nv162) II;ced-10(n3246) IV \\
\hline KU713 & juls76 II;ced-10(n3246) IV;Ex[Punc-25::max-2;:Pmyo-2::dsredmonomer] \\
\hline KU714 & juls76 max-2(nv162) II;Ex[Punc-25:::ced-10(GTP);Pmyo-2::dsredmonomer] \\
\hline KU715 & juls76 Il;ced-2(n1994) IV \\
\hline KU716 & juls76 Il;ced-5(n1812) IV \\
\hline KU717 & ced-12(k156) l;juls76 II \\
\hline KU718 & juls76 max-2(nv162) II;ced-5(n1812) IV \\
\hline KU719 & juls76 II;ced-5(n1812) IV;Ex[Punc-25::ced-10(GTP);Pmyo-2::dsredmonomer] \\
\hline KU720 & juls76 II;ced-5(n1812) IV;Ex[Punc-25::ced-10(GDP);Pmyo-2::dsredmonomer \\
\hline KU721 & juls76 Il;ced-5(n1812) IV;Ex[Punc-25::max-2;Pmyo-2::dsredmonomer] \\
\hline KU722 & src-1(cj293)/hT2[bli-4(e937) let-?(q782) qls48] (l;/ll);juls76 II \\
\hline KU723 & ina-1(gm39)/hT2[bli-4(e937) let-?(q782) qls48] (l,;ll);juls76 II \\
\hline KU724 & $\begin{array}{l}\text { ina-1(gm39)/hT2[bli-4(e937) let-?(q782) qls48] (li/ll);juls76 Il; } \\
\text { Ex[Punc-25::mlk-1(S355E);Pmyo-2::dsredmonomer }]\end{array}$ \\
\hline KU725 & $\begin{array}{l}\text { src-1(cj293)/hT2[bli-4(e937) let-?(q782) qls48] (l;ill);juls76 Il; } \\
\text { Ex[Punc-25:::mlk-1(S355E);Pmyo-2::dsredmonomer] }\end{array}$ \\
\hline KU726 & $\begin{array}{l}\text { ina-1(gm39)/hT2[bli-4(e937) let-?(q782) qls48] (l;ill);juls76 Il; } \\
\quad \text { Ex[Punc-25::max-2;Pmyo-2::dsredmonomer] }\end{array}$ \\
\hline KU727 & $\begin{array}{l}\text { src-1(j293)/hT2[bli-4(e937) let-?(q782) q/s48] (I;/lll);juls76 Il; } \\
\text { Ex[Punc-25:::max-2;:Pmyo-2::dsredmonomer] }\end{array}$ \\
\hline KU728 & ced-1(e1754) l;juls76 II \\
\hline KU729 & juls76 Il;ced-2(e1752) IV \\
\hline KU730 & juls76 Il;ced-5(n2002) IV \\
\hline KU731 & juls76 Il;ced-10(n1993) IV \\
\hline KU732 & ced-12(k149) l;juls76 II \\
\hline KU733 & dlk-1(km12) lijuls76 Il;Ex[Punc-25::max-2;:Pmyo-2::dsredmonomer] \\
\hline KU734 & $\max -2(n v 162)$ juls76 Il;Ex[dlk-1 fosmid;Pmyo-2::dsredmonomer] \\
\hline KU735 & juls76;ced-10(n3246) IV;Ex[Punc-25::ced-10(GTP);Pmyo-2::dsredmonomer] \\
\hline KU736 & juls76;ced-10(n3246) IV;Ex[Punc-25::ced-10(GDP);Pmyo-2::dsredmonomer] \\
\hline KU738 & $\begin{array}{l}\text { ina-1(gm39)/hT2[bli-4(e937) let-?(q782) qls48] (1;:Ill);juls76 Il; } \\
\text { Ex[Punc-25::ina-1;Pmyo-2::dsredmonomer] }\end{array}$ \\
\hline KU740 & N2;III [Punc-47::mcherry];Ex[Punc-25::ina-1::gfp;Pmyo-2::dsredmonomer $]$ \\
\hline KU741 & tpa-1(fr1) IV \\
\hline KU742 & $\max -2($ nv162) II;tpa-1(fr1) IV \\
\hline KU744 & juls76 Il;Ex[Punc-25::max-2;Pmyo-2::dsredmonomer] \\
\hline KU746 & juls76 II;mig-2(mu28) X \\
\hline KU505 & $d l k-1(k m 12)$ l;juls76II \\
\hline MJ500 & tpa-1(k501) IV \\
\hline
\end{tabular}

the dlk-1 gene (25 ng/ $\mu \mathrm{l})$ was used in kmEx524 [dlk-1 fosmid + Pmyo-2::dsredm] as described previously (Li et al., 2012). An extrachromosomal array carrying Pmax-2::flag::max-2 has been described previously (Fujiki et al., 2010).

Immunoblotting. Worm extracts were prepared by boiling harvested worms in SDS sample buffer. Standard techniques were used for immunoblotting (Kawasaki et al., 1999). Anti-phospho-KGB-1 (anti-pKGB-1) and anti-KGB-1 antibodies have been described previously (Mizuno et al., 2004).

Stress sensitivity. The assay for heavy metal toxicity $\left(100 \mu \mathrm{M} \mathrm{Cu}^{2+}\right)$ was performed as described previously (Mizuno et al., 2004).

Axotomy. Young adult or L4 stage hermaphrodite animals were immobilized with $20 \mathrm{~mm}$ levamisole solution in M9 buffer on a 2\% agarose pad under a coverslip. D-type motor neurons expressing green fluorescent protein (GFP) were imaged with a fluorescence microscope. Selected commissural axons, mainly posterior D-type neurons, were severed us- 
A

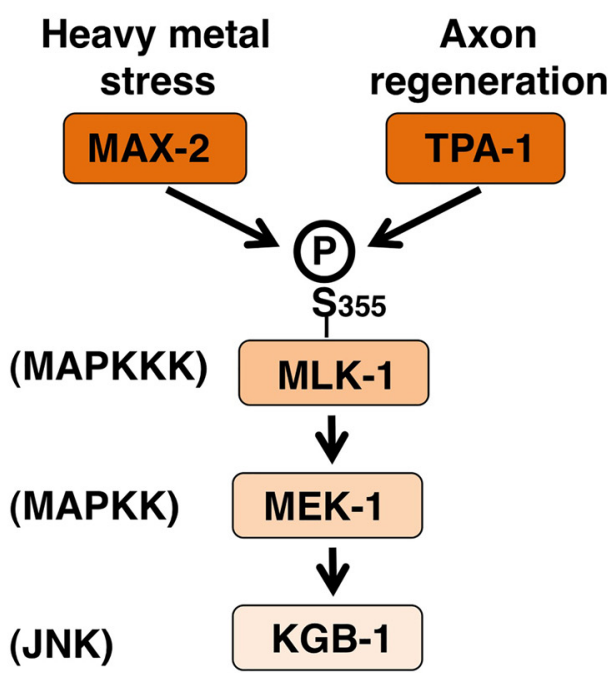

B
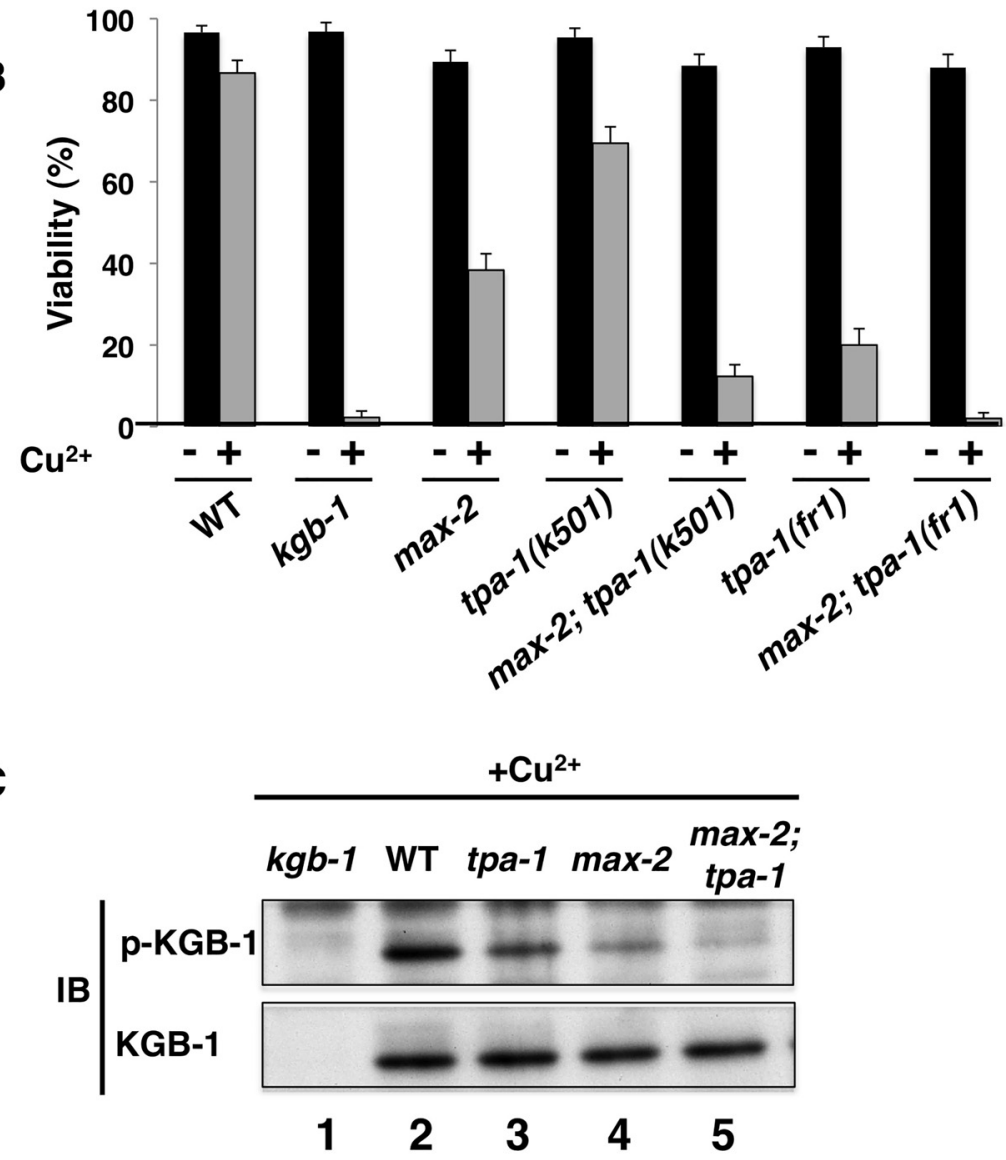

Figure 1. Heavy metal stress sensitivity in C. elegans mutants. A, Schematic diagram of the KGB-1-JNK pathway. B, Copper sensitivity. Each animal was cultured from embryogenesis on NGM plates containing $100 \mu \mathrm{M} \mathrm{Cu}{ }^{2+}(+)$ and seeded with bacteria of the OP50 strain. The percentages of worms reaching adulthood $4 \mathrm{~d}$ after egg laying are shown with SEs (error bars). WT, Wild-type. C, KGB-1 activity. N2 WT, kgb-1(km21), max-2(nv162), tpa-1(k501), and max-2(nv162);tpa-1(k501) animals were treated with $100 \mu \mathrm{M}$ Cu ${ }^{2+}$. Extracts prepared from each animal were immunoblotted with anti-pKGB-1 and anti-KGB-1 antibodies.

A

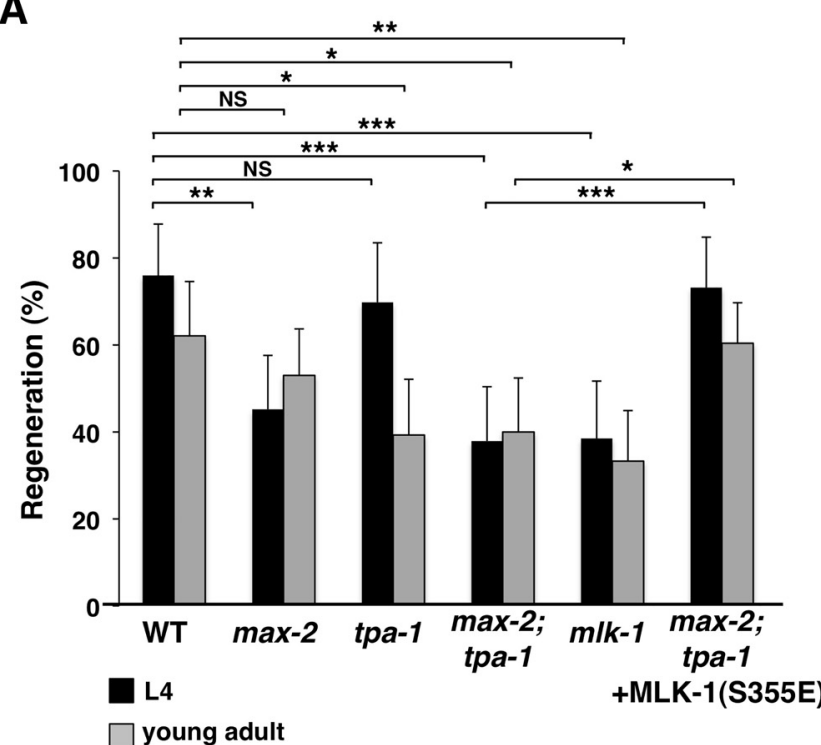

B

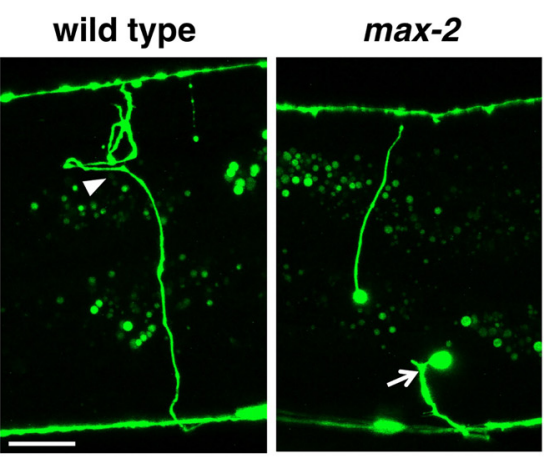

Figure 2. Effects of MAX-2 and TPA-1 on axon regeneration. $A$, Percentages of axons that initiated regeneration $24 \mathrm{~h}$ after laser surgery in $L 4$ or young adult stage. Error bars indicate $95 \%$ confidence intervals (Cl). ${ }^{*} p<0.05,{ }^{* *} p<0.01,{ }^{* * *} p<0.001$ as determined by Fisher's exact test. NS, Not significant. B, Representative D-type motor neurons in wild-type and max-2(nv162) mutant animals $24 \mathrm{~h}$ after laser surgery in $\mathrm{L} 4$ stage. In wild-type animals, the severed axon had regenerated growth cone (arrowhead). In max- 2 mutants, the severed axon failed to regenerate (arrow). Scale bar, $10 \mu \mathrm{m}$. 
Table 2. Raw data for axon regeneration

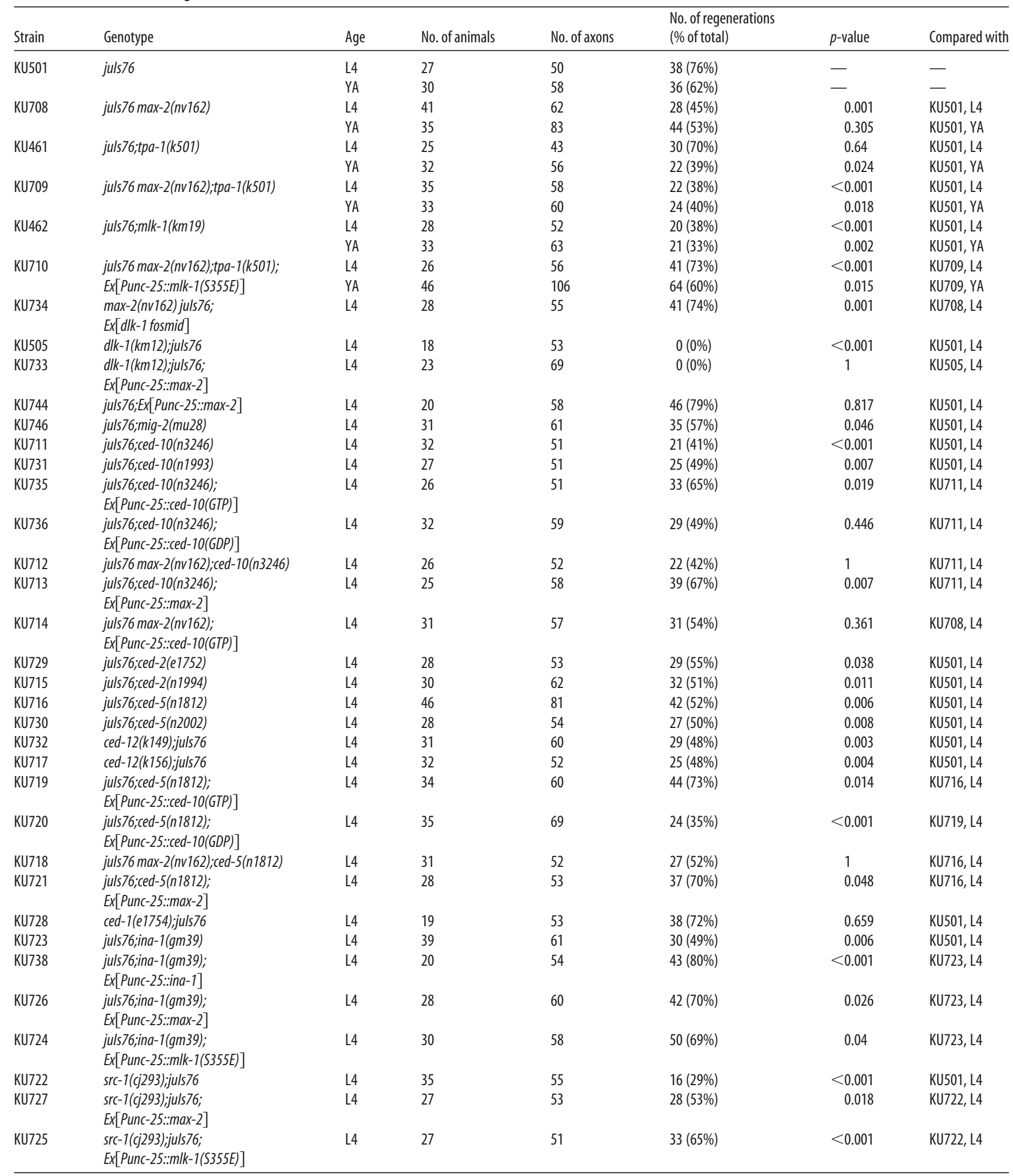

ing a $440 \mathrm{~nm}$ MicroPoint ablation Laser System from Photonic Instruments. The animals were transferred to an agar plate and remounted for fluorescent imaging $\sim 24 \mathrm{~h}$ after surgery. Both Zeiss Axioplan fluorescent and Olympus FV-500 confocal laser microscopes were used for observation. Axons that grew a distance of $5 \mu \mathrm{m}$ or more were scored as regenerated. The proximal axon segments that showed no change after $24 \mathrm{~h}$ were counted as not regenerated. At least 20 animals with one to two axotomized commissures were observed for most experiments. Twotailed $p$-values were calculated using Fisher's exact test.

Microscopy. Standard fluorescent images of transgenic animals were observed under a Zeiss Plan-APOCHROMAT X100 objective of a Zeiss Axioplan II fluorescent microscope and photographed with a Hamamatsu 3CCD camera. Confocal fluorescent images were taken on an Olympus FV-500 confocal laser-scanning microscope with a $100 \times$ objective. 
A p38 pathway JNK pathway
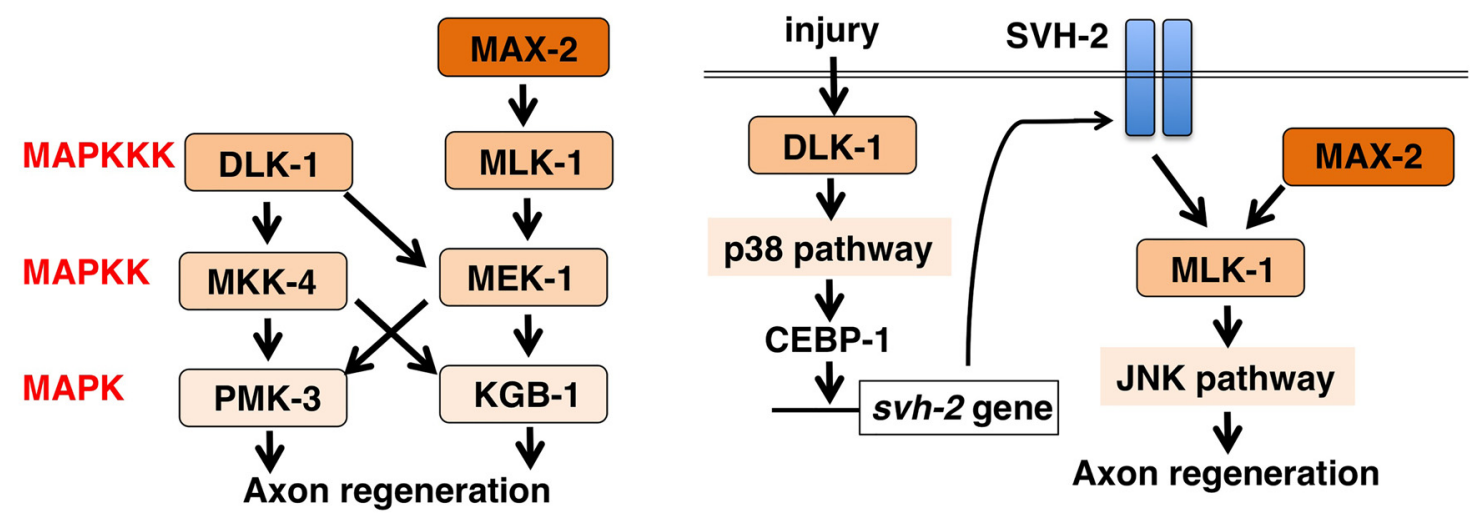

B

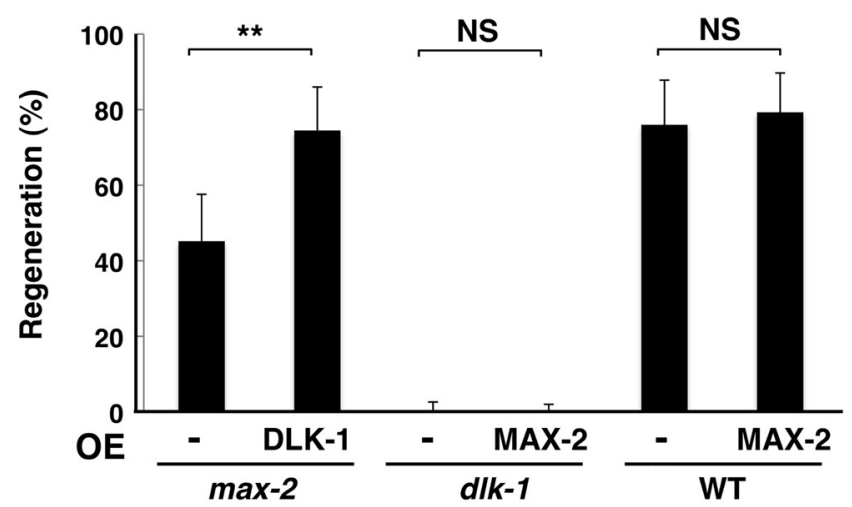

Figure 3. Effects of max-2 and dlk-1 overexpression on axon regeneration. $A$, Relationship between the JNK and p38 MAPK pathways that regulate axon regeneration in C. elegans. Left, Diagram of the two MAPK pathways essential for axon regeneration, with crosstalk between kinases indicated with arrows. Right, DLK-1-p38 MAPK pathway activates axon injuryinduced expression of svh-2 via the bZip transcription factor CEBP-1. B, Percentages of axons that initiated regeneration $24 \mathrm{~h}$ after laser surgery in L4 stage are shown. Error bars indicate $95 \%$ confidence intervals $(\mathrm{Cl}) .{ }^{* *} p<0.01$ as determined by Fisher's exact test. NS, Not significant.

Localization of INA-1::GFP in growth cones. Two or three axons in L4 stage hermaphrodite N2;In[Punc-47::mcherry]; Ex[Punc-25::ina-1::gfp + Pmyo-2::dsred] animals were axotomized as described above and imaged $6 \mathrm{~h}$ later with an FV-500 confocal laser microscope. Nonaxotomized L4 stage animals served as a control. For each axotomized axon, the fold enrichment (FE) of INA-1::GFP in proximal ends of injured axons, FE(INA-1) end, was calculated as follows:

$(\mathrm{GFP} \text { to } \mathrm{mCherry})_{\mathrm{end}}=\left(\mathrm{GFP}_{\text {end }}-\mathrm{GFP}_{\text {background }(\mathrm{bg}))}\right.$

$$
/\left(\mathrm{mCherry}_{\mathrm{end}}-\text { mCherry }_{\mathrm{bg}}\right)
$$

$(\mathrm{GFP} \text { to } \mathrm{mCherry})_{\mathrm{axon}}=\left(\mathrm{GFP}_{\mathrm{axon}}-\mathrm{GFP}_{\mathrm{bg}}\right)$

$$
/\left(\text { mCherry }_{\text {axon }}-\text { mCherry }_{\mathrm{bg}}\right)
$$

$\mathrm{FE}(\mathrm{INA}-1)_{\text {end }}=(\text { GFP to mCherry })_{\text {end }} /(\text { GFP to mCherry })_{\text {axon }}$

$\mathrm{GFP}_{\text {end }}, \mathrm{GFP}_{\mathrm{axon}}$, and $\mathrm{GFP}_{\mathrm{bg}}$ were the mean fluorescent intensities of GFP in the proximal end of the injured axon and the proximal fragment of the axotomized axon excluding the proximal end and the background, respectively. $\mathrm{mCherry}_{\mathrm{end}}, \mathrm{mCherry}_{\mathrm{axon}}$, and $\mathrm{mCherry}_{\mathrm{bg}}$ were the corresponding mean intensities of mCherry in the proximal end of the injured axon and the axon region below the proximal end and the background, respectively. All fluorescent intensities were measured with ImageJ. To calculate $\mathrm{FE}(\mathrm{INA}-1)_{\text {end }}$ for nonaxotomized axons, a region of the axon near the midline, which corresponded to the site of axotomy, was marked $\mathrm{GFP}_{\text {end }}$ and $\mathrm{mCherry}_{\text {end }}$ and the region of the axon below it was used to measure $\mathrm{GFP}_{\text {axon }}$ and mCherry ${ }_{\text {axon }}$. The difference between FE (INA-1) $)_{\text {end }}$ for axotomized and nonaxotomized axons was tested for statistical significance with Mann-Whitney test. The box plot for FE(INA-1) end was made with R-studio (http://www.rstudio.com/).
Yeast two-hybrid assay. The Saccharomyces cerevisiae reporter strain PJ69-4A (James et al., 1996) was cotransformed with plasmids expressing the GAL4 DBD-CED-10(G12V or T17N) and GAL4 AD-MAX-2(fulllength or CRIB) fusion proteins. The transformants were plated onto synthetic medium lacking histidine and incubated at $30^{\circ} \mathrm{C}$ for $4 \mathrm{~d}$. Interaction of the pairs of fusion proteins transactivates the HIS3 reporter gene and allows their growth on the plate.

Counting of apoptotic cells. Differential interference contrast images of at least 20 animals in each of the 1.5-fold and 2-fold stages were obtained and apoptotic cells were counted.

\section{Results}

TPA-1 functions redundantly with MAX-2 in the KGB-1-JNK pathway to regulate the stress response to heavy metals

We have shown previously that MAX-2, a C. elegans Ste20-related protein kinase, acts upstream of MLK-1 in the stress response to heavy metals by phosphorylating it on Ser-355 (Fujiki et al., 2010). This phosphorylation is important for the activation of MLK-1 kinase activity in the KGB-1 pathway (Fig. 1A). However, animals with a max-2(nv162)-null mutation remain partially resistant to stress induced by copper ions $\left(\mathrm{Cu}^{2+}\right)$ (Fig. $\left.1 B\right)$ (Fujiki et al., 2010), raising the possibility that another protein kinase may play a redundant role with MAX-2 in mediating the response to heavy metals. In addition to the heavy metal stress response, the $C$. elegans MLK-1-MEK-1-KGB-1 pathway also regulates axon regeneration ( $\mathrm{Nix}$ et al., 2011). In axon regeneration, TPA-1, a C. elegans PKC, interacts with and phosphorylates MLK-1 at the Ser-355 residue (Pastuhov et al., 2012). We therefore investigated whether TPA-1 is also involved in the KGB-1- 
A

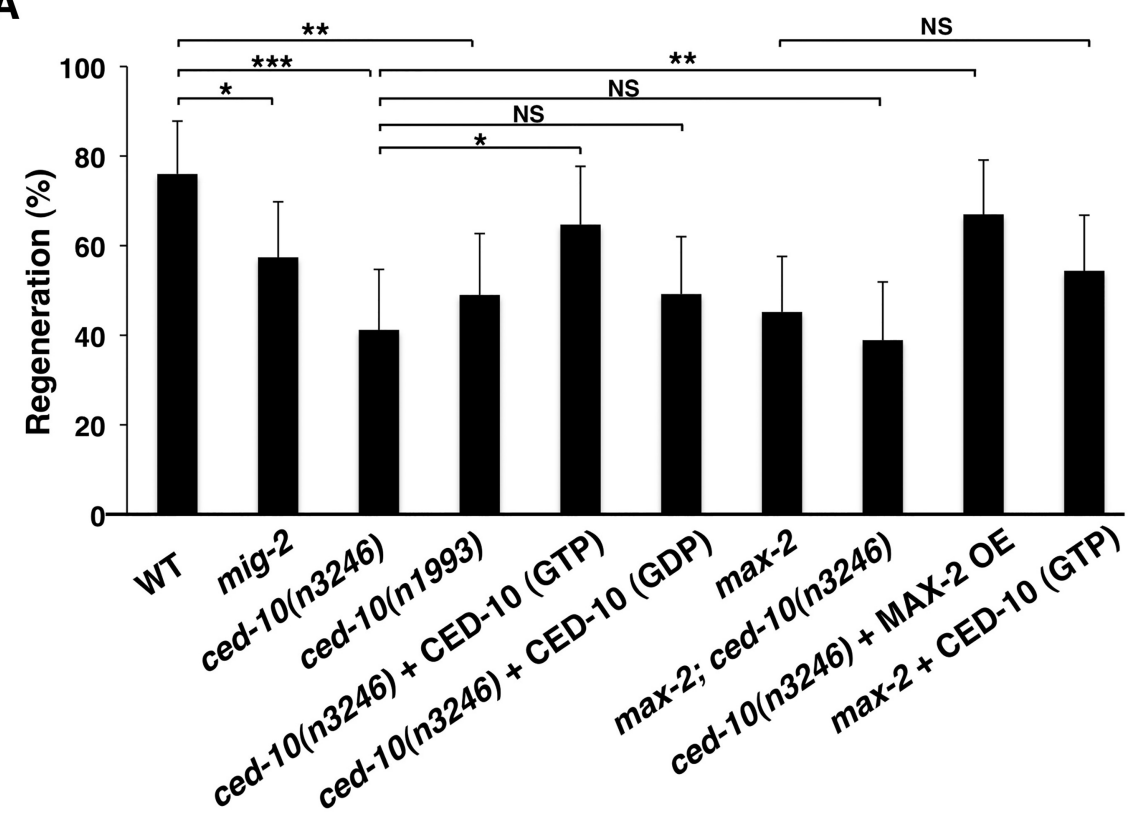

B

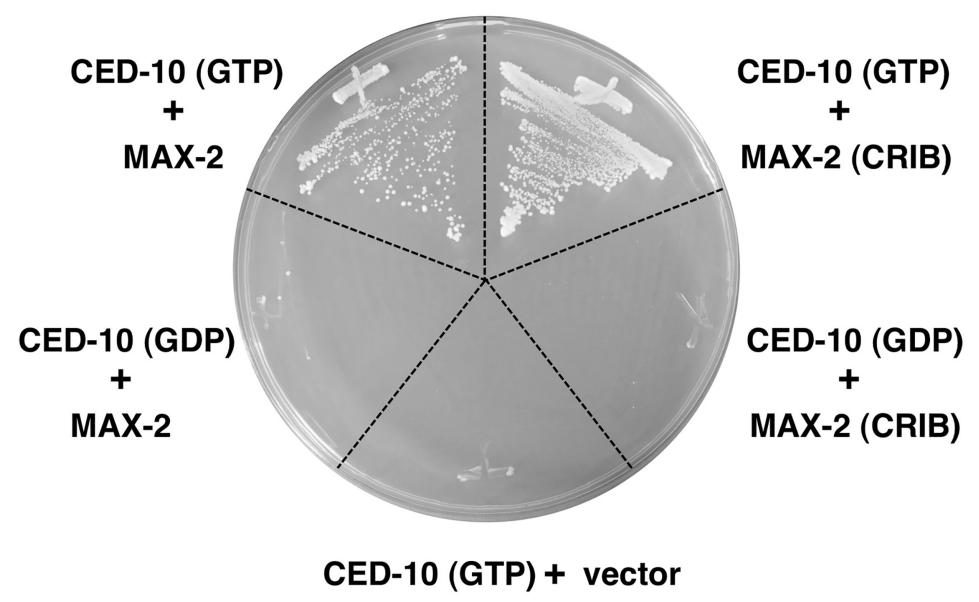

Figure 4. Effect of CED-10 on axon regeneration. $\boldsymbol{A}$, Percentages of axons that initiated regeneration $24 \mathrm{~h}$ after laser surgery in $\mathrm{L} 4$ stage. Error bars indicate $95 \%$ confidence intervals (CI). ${ }^{*} p<0.05,{ }^{* *} p<0.01,{ }^{* * *} p<0.001$ as determined by Fisher's exact test. NS, Not significant. $\boldsymbol{B}$, Two-hybrid assay for the interaction of MAX-2 with CED-10. The reporter strain PJ69-4A was cotransformed with expression vectors encoding GAL4 DBD-CED-10(T19N) (GDP), GAL4 DBD-CED-10(G14V) (GTP), GAL4 AD-MAX-2, and GAL4 AD-MAX-2(CRIB) as indicated.

mediated stress response pathway. The $k 501$ allele of the tpa-1 gene contains a missense mutation causing a change of the proline at 544 in the kinase domain to a serine. Animals carrying the tpa-1(k501) mutation were placed on agar plates containing a high $\mathrm{Cu}^{2+}$ concentration and their development monitored for any signs of an altered response to $\mathrm{Cu}^{2+}$. We found that tpa1 (k501) mutants were weakly sensitive to $\mathrm{Cu}^{2+}$ compared with wild-type animals (Fig. 1B). To test whether TPA-1 regulates the heavy metal stress response redundantly with MAX-2, we constructed max-2(nv162); tpa-1(k501) double mutants and found that these showed $\mathrm{Cu}^{2+}$ sensitivity stronger than the single max$2(n v 162)$ mutant (Fig. 1B). Sensitivity to $\mathrm{Cu}^{2+}$ was also observed in tpa-1( $f r 1)$ mutants (Fig. $1 B$ ). The fr 1 allele contains a nonsense mutation, which results in a premature stop codon at Trp-187, suggesting that $f r 1$ is probably a null mutation. We found that max-2(nv162); tpa-1(fr1) double mutants showed enhanced $\mathrm{Cu}^{2+}$ sensitivity, which was similar to that observed in $k g b-1$ mutants (Fig. 1B). Therefore, TPA-1 and MAX-2 regulate the response to $\mathrm{Cu}^{2+}$ stress redundantly.

To verify the redundancy of TPA-1 with MAX-2 in the KGB-1 pathway, we examined KGB-1 activation. KGB-1 is activated by MEK-1-mediated phosphorylation at the Ser-198 and Tyr-200 residues located in the KGB-1 kinase domain (Mizuno et al., 2004, 2008). The anti-pKGB-1 antibody, which recognizes the phosphorylated form of KGB-1, was used to monitor KGB-1 activation in C. elegans. Western blot analysis with anti-pKGB-1 antibody clearly detected the phosphorylated form of KGB-1 in wild-type animals treated with $\mathrm{Cu}^{2+}$ ions (Fig. $1 C$, lane 2). In contrast, animals harboring the $k g b-1(k m 21)$ deletion mutation exhibited undetectable levels of KGB-1 protein expression or activation (Fig. $1 C$, lane 1 ). In the single max-2(nv162) or tpa-1(k501) mutants, phosphorylation of KGB-1 in response to $\mathrm{Cu}^{2+}$ treatment was somewhat lower than wild-type (Fig. 1C, lanes 3 and 4). However, in the max-2(nv162); tpa-1(k501) double mutants, KGB-1 activity was markedly reduced compared with either single mutant (Fig. 1C, lane 5). Together, these results suggest that MAX-2 and TPA-1 activate the KGB-1 response to heavy metal stress redundantly by directly phosphorylating MLK-1 Ser-355 and upregulating MLK-1 kinase activity.

\section{MAX-2 and TPA-1 regulate axon regeneration mainly in the $\mathrm{L} 4$ and young adult developmental stages, respectively}

As observed previously (Pastuhov et al., 2012), axon regeneration in tpa-1(k501) mutants was reduced only in young adult animals, not in L4 larvae (Fig. 2A, Table 2). Therefore, TPA-1 is required mainly in the adult stage for axon regeneration of D-type motor neurons after laser surgery. In contrast, MLK-1 is required for axon regeneration at both stages (Fig. 2A, Table 2), suggesting that another factor may act as an activator of MLK-1 to promote axon regeneration mainly in the L4 stage. Our analysis of MAX-2 raised the possibility that it might be a candidate for such an MLK-1 activator. To test this possibility, we investigated whether MAX-2 is involved in the KGB-1-mediated axon regeneration pathway. Although the axon guidance defect was observed in max-2(nv162) mutants (Lucanic et al., 2006), we found that the D-type motor neurons of max$2(n v 162)$ mutants in the L4 stage were impaired in their regeneration response (Fig. $2 A, B$, Table 2). This result is consistent with a recent report of extensive screening by Nix et al. (2014). Furthermore, Chen et al. (2011) performed a systematic screen of mutants looking for defects in axon regeneration and identified 
max-2 among several genes that regulate axon regeneration positively in a glutamatergic touch sensory neuron. These results support the idea that MAX-2 is generally required during regeneration. The effect of the max-2 mutation on axon regeneration in the L4 stage was stronger than that in the young adult stage (Fig. 2A, Table 2). In addition, the max-2;tpa-1 double mutants were defective in axon regeneration in both the $\mathrm{L} 4$ and adult stages (Fig. 2A, Table 2). However, the axon guidance defect observed in max-2(nv162) mutants was not enhanced by the tpa1(k501) mutation. Therefore, MAX-2 and TPA-1 regulate axon regeneration mainly in the L4 and adult stages, respectively. Although the expression levels of the max-2 gene in whole animals are constant during various developmental stages (Spencer et al., 2011), it has been shown that max-2 is expressed in ventral cord neurons during early development, but not at the young adult stage (Lucanic et al., 2006). These results suggest that TPA- 1 takes the place of MAX-2 to activate MLK-1 in axon regeneration at the adult stage.

We next investigated whether MLK-1 functions downstream of MAX-2 in axon regeneration. We generated a phosphomimetic form of MLK-1 [MLK-1(S355E)] in which Ser-355 has been mutated to glutamate. We found that the expression of MLK-1(S355E) by the unc-25 promoter in D-type neurons was able to suppress the regeneration defect of max-2;tpa-1 double mutants at either the L4 or adult stage (Fig. 2A, Table 2). These results suggest that MLK-1 functions cell autonomously downstream of MAX-2.

C. elegans axon regeneration is regulated by the $\mathrm{p} 38$ and JNKMAPK pathways, which consist of DLK-1 (MAPKKK)-MKK-4 (MAPKK)-PMK-3 (p38 MAPK), and MLK-1(MAPKKK)MEK-1(MAPKK)-KGB-1 (JNK-MAPK), respectively (Fig. 3A) (Hammarlund et al., 2009; Yan et al., 2009; Nix et al., 2011). We have shown previously that there is cross talk between the PMK-3 and KGB-1 MAPK pathways (Nix et al., 2011). Overexpression of dlk-1 can activate the KGB-1 pathway by cross-activating MEK-1 (Fig. 3A). Consistent with this, we found that $d l k-1$ overexpression suppressed the regeneration defect in max-2 mutants (Fig. $3 B$, Table 2). In addition, we have demonstrated that the DLK-1p38 MAPK pathway activates axon injury-induced expression of svh-2 via the bZip transcription factor CEBP-1 (Fig. 3A) (Li et al., 2015). The $s v h-2$ gene encodes a Met-like receptor tyrosine kinase, which activates the KGB-1-JNK pathway through tyrosine phosphorylation of MLK-1 (Li et al., 2012). Activation of the MLK-1-MEK-1 pathway requires the dual phosphorylation of MLK-1; that is, SVH-2-mediated tyrosine phosphorylation and MAX-2-mediated serine phosphorylation. In dlk-1 mutants, svh-2 is not induced by axon injury (Li et al., 2015). Therefore, it can be expected that tyrosine phosphorylation of MLK-1 may not occur in $d l k-1$ mutants overexpressing MAX-2. As expected, we found that overexpression of max-2 by the unc- 25 promoter was unable to suppress the regeneration defect in $d l k-1$ mutants (Fig. $3 B$, Table 2). Axons in wild-type animals overexpressing MAX-2 regenerated normally (Fig. 3B, Table 2).

\section{CED-10 functions upstream of MAX-2 in axon regeneration}

MAX-2 is a member of the PAK (p21-activated kinase) family, which is regulated by small GTPases (Fujiki et al., 2010). These GTPases act as molecular switches that interconvert between two states: the active, GTP-bound state and the inactive, GDP-bound state. PAKs have been shown to bind to the GTP-bound form of Cdc42/Rac family GTPases through an N-terminal Cdc42/Racinteractive binding (CRIB) domain (Dan et al., 2001) and MAX-2 also contains this CRIB motif (Fujiki et al., 2010). In the stress
Table 3. Numbers of apoptotic cells at embryonic stages

\begin{tabular}{|c|c|c|c|c|}
\hline \multirow[b]{2}{*}{ Genotype } & \multicolumn{4}{|l|}{ No. of cell corpses } \\
\hline & 1.5 -fold & $n$ & 2 -fold & $n$ \\
\hline Wild-type & $10.1 \pm 1.0$ & 20 & $10.7 \pm 1.2$ & 20 \\
\hline ced-10 (n3246) & $24.9 \pm 2.6^{\mathrm{a}}$ & 20 & $27.3 \pm 2.2^{\mathrm{a}}$ & 20 \\
\hline $\max -2(n v 162)$ & $12.2 \pm 1.4^{\mathrm{a}}$ & 20 & $13.7 \pm 3.1^{\mathrm{a}}$ & 20 \\
\hline max-2 (nv162);ced-10(n3246) & $43.5 \pm 2.9^{b}$ & 20 & $46.8 \pm 4.3^{b}$ & 20 \\
\hline ced-10(n3246) + MAX-2 OE & $24.9 \pm 2.5$ (NS1) & 20 & $26.8 \pm 3.0$ (NS1) & 20 \\
\hline mlk-1 (km19) & $9.8 \pm 1.2$ (NS2) & 20 & $10.7 \pm 1.8$ (NS2) & 20 \\
\hline
\end{tabular}

The number of cell corpses in each genotype was scored at the indicated stage. All comparisons were performed by unpaired $t$ test. Data are presented as mean \pm SD.

${ }^{a} p<0.001$ versus wild type.

${ }^{\mathrm{b}} p<0.001$ versus ced-10(n3246) mutant.

NS1, Not significant versus ced-10(n3246) mutant; NS2, not significant versus wild-type.

response pathway, the GTP-bound form of the Rac-type GTPase MIG-2 interacts with and activates MAX-2 (Fujiki et al., 2010). We therefore investigated whether MIG-2 would also be involved in the axon regeneration pathway, but found that the mig$2($ mu28) mutation had only a weak effect on axon regeneration (Fig. 4A, Table 2). However, we found that another Rac-type GTPase, CED-10, was able to bind to MAX-2. Using a yeast twohybrid assay, we observed that MAX-2 interacted through its CRIB domain with the activated, GTP-bound form of CED-10, but not with the GDP-bound form (Fig. 4B).

We next investigated whether CED-10 functions in axon regeneration. We observed that animals harboring the ced-10(n3246) mutation exhibited a decrease in the axon regeneration of D-type motor neurons (Fig. $4 A$, Table 2). The $n 3246$ allele replaces a glycine at 60 with arginine. Because Nix et al. (2014) reported that the ced-10 mutation had no effect on axon regeneration, we examined a different allele of the ced-10 gene, $n 1993$. The $n 1993$ allele replaces a valine at 128 with glycine. The ced-10(n1993) mutant was also defective in axon regeneration (Fig. $4 A$, Table 2). It can be expected that CED-10 cycles between the GTP-bound active and the GDP-bound inactive forms. Consistent with this, we found that expression of the GTPbound active CED-10(G12V) by the unc-25 promoter in D-type neuron, but not of the GDP-bound inactive CED-10(T17N), was able to rescue the ced-10 defect in axon regeneration (Fig. 4A, Table 2). Furthermore, the ced-10(n1993 or $n 3246)$ mutation had no effect on the morphology of D-type motor neurons. These results suggest that $\mathrm{CED}-10$ acts to promote regeneration in the damaged neuron in a cell-autonomous manner.

To address whether ced-10 and max-2 function in the same pathway, we constructed max-2(nv162);ced-10(n3246) double mutants. The double mutants did not show any enhanced defect in axon regeneration compared with the single max-2(nv162) or ced10(n3246) mutants (Fig. 4A, Table 2), suggesting that CED-10 and MAX-2 function in the same pathway. Furthermore, we found that overexpression of the max-2 gene from the unc-25 promoter in Dtype motor neurons was able to suppress the ced-10 defect, whereas expression of GTP-bound active CED-10(G12V) from the unc-25 promoter failed to suppress the max-2 defect (Fig. 4A, Table 2). These results suggest that MAX-2 functions cell autonomously downstream of CED-10 in the axon regeneration pathway.

Previous genetic analyses have shown that CED-10 is important for the engulfment of apoptotic cells during development (Hsu and $\mathrm{Wu}, 2010)$. We therefore investigated whether MAX-2 and MLK-1 would be required for the removal of apoptotic cells. A time course analysis of the number of cell corpses present during embryogenesis showed no obvious difference between $m l k-1(k m 19)$ mutants and wild-type animals at both the 1.5-fold and 2-fold stages (Table 3). In contrast, 
A
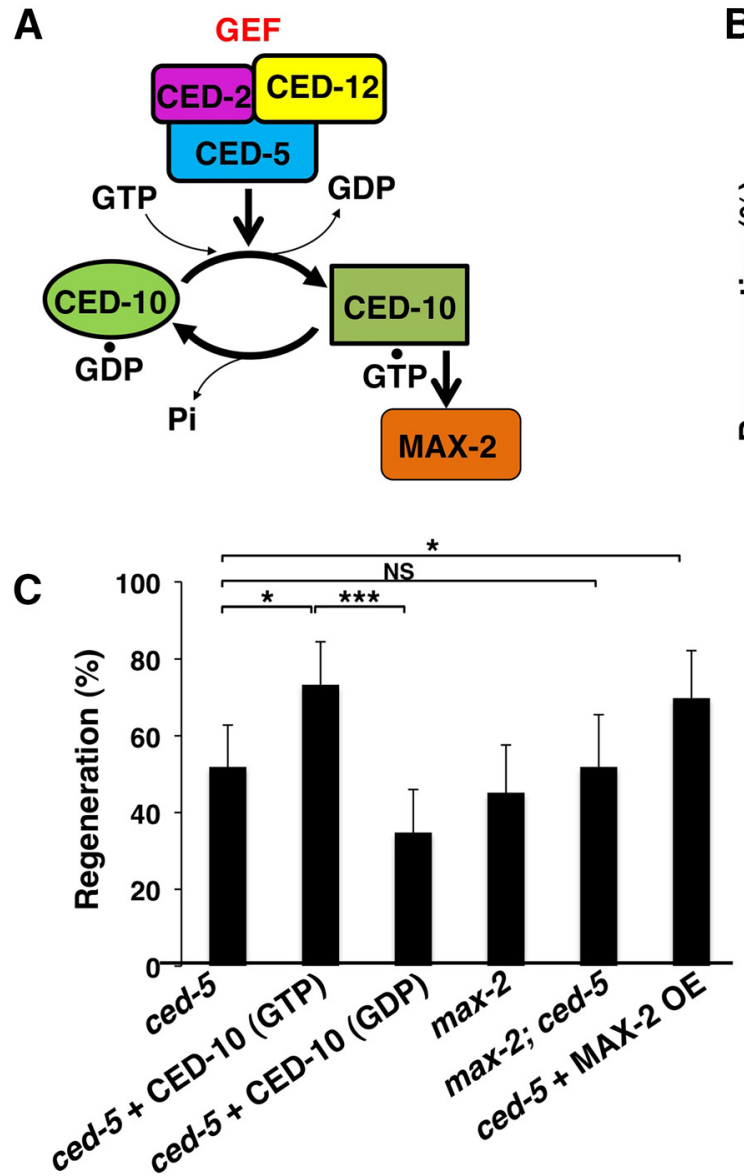

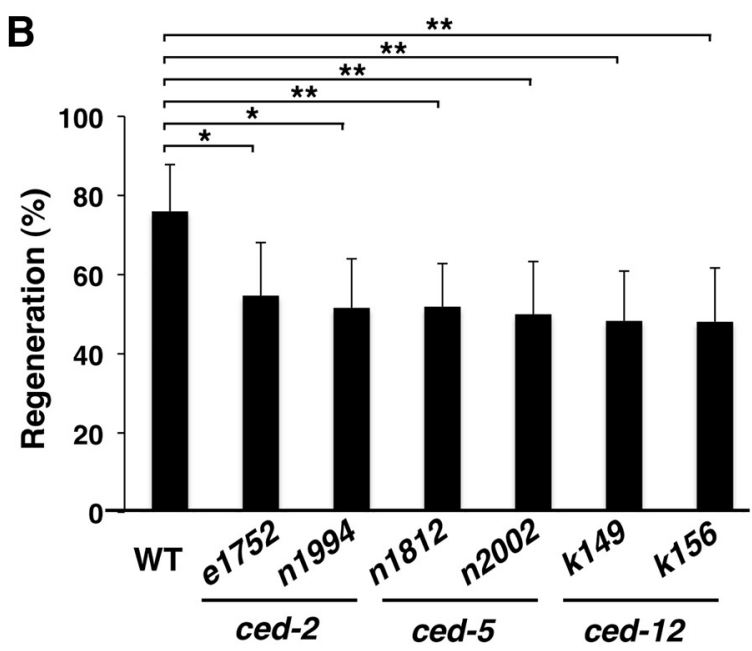

Figure 5. Effect of the signaling module CED-2-CED-5-CED-12 on axon regeneration. $A$, The CED-2-CED-5-CED-12 complex functioning upstream of CED-10. In the molecular pathway regulating the engulfment of dead cells in C. elegans, the CED-2-CED-5-CED-12 complex acts as a GEF for CED-10. B, C, Percentages of axons that initiated regeneration $24 \mathrm{~h}$ after laser surgery in L4 stage. Error bars indicate $95 \%$ confidence intervals $(\mathrm{Cl}) .{ }^{*} p<0.05,{ }^{* *} p<0.01,{ }^{* * *} p<0.001$ as determined by Fisher's exact test. NS, Not significant.

both the ced-10(n3246) and max-2(nv162) mutations caused an increase in the number of cell corpses (Table 3 ). However, we found that the max-2 mutation enhanced the defect in engulfment of apoptotic cells in ced-10 mutants (Table 3 ). Furthermore, overexpression of $\max -2$ by its own promoter failed to suppress the ced-10 defect in engulfment of apoptotic cells (Table 3 ). These results suggest that MAX-2 and CED-10 function in independent pathways for cell corpse engulfment. Therefore, in the engulfment pathway, the CED-10 GTPase does not transduce signals to the JNK pathway.

\section{CED-2, CED-5, and CED-12 act upstream of CED-10 in} axon regeneration

In the engulfment pathway, CED-10 GTPase is activated by the intracellular signaling proteins CED-2, CED-5, and CED-12 (Fig. 5A) (Hsu and Wu, 2010). CED-2, CED-5, and CED-12 are similar to the $\mathrm{SH} 2-\mathrm{SH} 3$ domain-containing adaptor protein CrkII, Dock180, and ELMO, respectively (Wu and Horvitz, 1998; Reddien and Horvitz, 2000, 2004; Gumienny et al., 2001). In mammals, Dock180 and ELMO form a complex that functions as a guanine nucleotide exchange factor (GEF) for Rac-GTPases (Brugnera et al., 2002). It has been proposed that CED-5/Dock180 and CED-12/ELMO may interact with CED-2/CrkII to form a trimeric complex and activate the CED-10/Rac (Gumienny et al., 2001; Wu et al., 2001). We therefore next investigated whether CED-2, CED-5, and CED-12 function in axon regeneration. We used two different mutant alleles of each gene, which are all nonsense mutations. The e1752 and $n 1994$ alleles encode CED-2 proteins that terminate at Trp-153 and Arg-102, respectively. The $n 1812$ and $n 2002$ alleles terminate at Glu-28 and Arg-962, respectively, of the CED-5 protein. The $k 149$ and $k 156$ alleles terminate at Arg-38 and Trp-195, respectively, of the CED-12 protein. We observed that all of these mutants showed a lower frequency of axon regeneration after neuronal injury compared with wildtype animals (Fig. 5B, Table 2). Furthermore, none of the ced-2, ced-5, or ced-12 mutations had any apparent effect on the morphology of D-type motor neurons.

If the CED-2-CED-5-CED-12 complex functions in axon regeneration as a GEF to activate CED-10, then we would expect that the expression of a constitutively active mutant of CED-10 would suppress the ced-5 phenotype. We expressed CED-10(G12V), a mutant CED-10 locked in the GTP-bound state, in D-type motor neurons using the $u n c-25$ promoter and found that it indeed suppressed the ced-5 defect in axon regeneration (Fig. 5C, Table 2). In contrast, similar expression of CED-10(T17N), a GDP-bound inactive form, did not suppress ced-5 (Fig. $5 C$, Table 2). Furthermore, we found that the max-2(nv162);ced-5(n1812) double mutants were no more defective in axon regeneration than the single ced-5(n1812) mutant. In addition, this ced-5 defect was suppressed by overexpression of the max-2 gene from the $u n c-25$ promoter in D-type neurons (Fig. 5C, Table 2). These results suggest that the CED-2-CED-5-CED-12 complex acts as a GEF for the 
CED-10 GTPase and functions cell autonomously upstream of MAX-2 in the axon regeneration pathway.

\section{INA-1 and SRC-1 regulate axon} regeneration upstream of the JNK pathway

In the apoptotic cell engulfment pathway in C. elegans, the CED-1 receptor or the integrin $\alpha$-subunit INA-1 functions upstream of CED-10 (Fig. 6A) (Zhou et al., 2001; Hsu and $\mathrm{Wu}, 2010)$. To investigate which receptor acts in the CED-10 pathway leading to axon regeneration, we examined ced-1(e1754) and the ina1 ( gm39) mutants. The e1754 allele of the ced-1 gene contains a nonsense mutation, which causes termination of the protein at Gln-32. The gm39 allele is the ina-1 weak mutant allele, which encodes a substitution of the amino acid from glycine to glutamic acid at 119 (Baum and Garriga, 1997). Although the ced-1 mutation had no effect on axon regeneration, we found that the frequency of axon regeneration after axon injury was lower in ina-1 (gm39) mutants compared with wildtype animals (Fig. $6 B$, Table 2). The ina1 (gm39) mutation did not affect the morphology of D-type motor neurons. To determine whether INA- 1 can act in a cellautonomous manner, we expressed the ina-1 $\mathrm{cDNA}$ from the unc-25 promoter in ina-1( gm39) mutants. The ina-1 defect was rescued by expression of ina-1 in D-type motor neurons (Fig. 6B, Table 2). These results demonstrate that INA-1 functions cell autonomously.

To determine whether ina-1 acts upstream of the JNK pathway in axon regeneration, we overexpressed MAX-2 in D-type motor neurons from the unc-25 promoter. Overexpression of max-2 significantly rescued the axon regeneration defect seen in ina-1 (gm39) mutants (Fig. 6B, Table 2). In addition, we found that expression of a phosphomimetic form of MLK-1 [MLK1 (S355E)] in D-type motor neurons by the unc-25 promoter also suppressed the ina-1 defect (Fig. 6B, Table 2). These observations suggest that INA-1 likely acts upstream of MAX-2 and MLK-1 in axon regeneration.

We next examined INA-1 localization in D-type motor neurons during axon regeneration. For this purpose, we expressed the Punc-25::ina-1::gfp gene in wild-type animals and performed fluorescent imaging analysis in D-type neurons. In the absence of axon injury, we observed that INA-1::GFP distributed uniformly throughout D-type motor axons (Fig. 7A). At $6 \mathrm{~h}$ after laser ablation of the axons, significant amounts of INA-1::GFP accumulated at the proximal ends of the injured axons (Fig. $7 A, B$ ).

Previous genetic and biochemical analyses have shown that the nonreceptor tyrosine kinase SRC-1 mediates apoptotic cell engulfment signaling from the INA-1 cytoplasmic domain to CED-2, a component of the CED-2-CED-5-CED-12 module that activates CED-10 (Fig. 6A) (Hsu and Wu, 2010). We therefore investigated whether $s r c-1$ participates in axon regeneration. The $c j 293$ allele of the $s r c-1$ gene encodes a protein that is deleted between aa 136 and 337, essentially a truncation at 137 . Therefore, this mutation lacks the $\mathrm{SH} 2$ and kinase domains, suggesting that the cj293 allele is null. The $s r c-1$ (cj293) mutant had a slight defect in axonal guidance during development. We found that the $\operatorname{src-1}$ (cj293) mutation was indeed defective in axon regeneration (Fig. 6B, Table 2). Similar to ina-1 mutants, the $s r c-1$ defect in axon regeneration was also suppressed by overexpression of MAX-2 or expression of MLK-1(S355E) in D-type motor neurons from the unc-25 promoter (Fig. $6 B$, Table 2). Therefore, SRC-1 regulates axon regeneration upstream of MAX-2 and MLK-1. Together, these results suggest that INA-1 and SRC-1 act upstream of the JNK pathway in axon regeneration. The src1(cj293) mutation caused a greater reduction in regeneration than the ina-1 (gm39) mutation. Although this could be due to a difference in allele strength, it also raises the possibility that SRC-1 may mediate signals from sources other than INA-1.

\section{Discussion}

The C. elegans JNK pathway is composed of MLK-1 MAPKKK, MEK-1 MAPKK, and KGB-1-JNK and regulates both the stress response to heavy metals and axon regeneration (Mizuno et al., 2004; Nix et al., 2011). MLK-1 is activated by phosphorylation of Ser-355 in the activation loop of its kinase domain. In the stress response to heavy metals, phosphorylation of MLK-1 on Ser-355 is catalyzed by the Ste20-related kinase MAX-2 (Fujiki et al., 
A

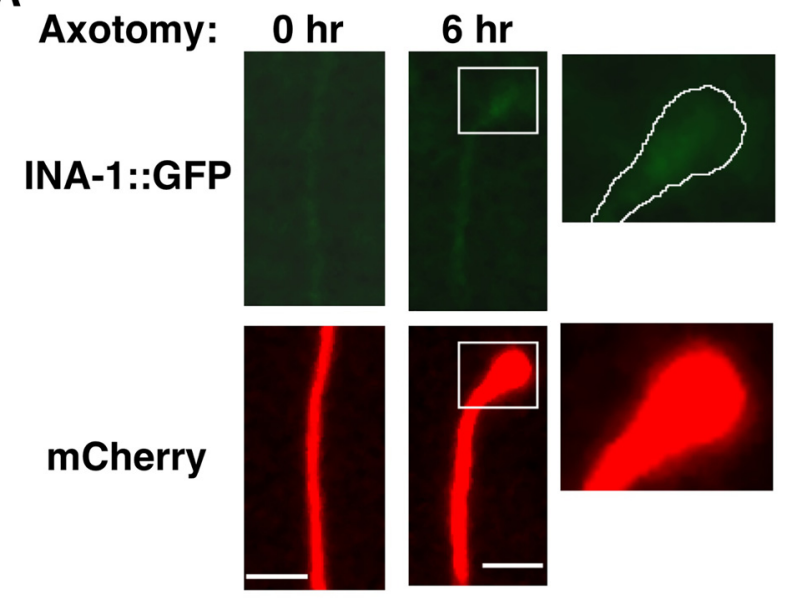

B

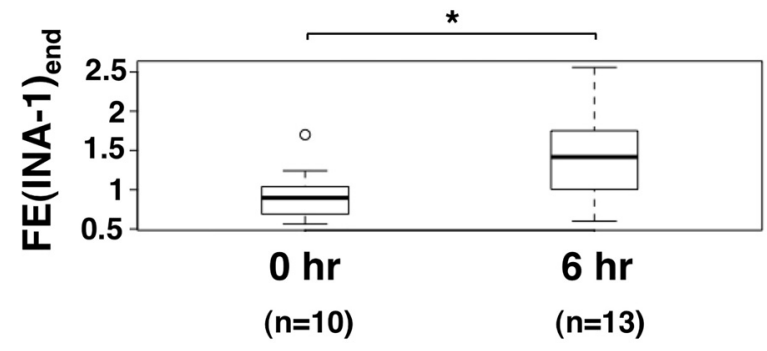

Figure 7. Localization of INA-1::GFP in D-type motor neurons after axon injury. $\boldsymbol{A}$, Fluorescent images of axons before $(0 \mathrm{~h})$ and $6 \mathrm{~h}$ after laser surgery in wild-type animals carrying Punc-25::ina-1::gfp and Punc-47::mcherry are shown. The proximal end of the injured axon is boxed (middle) and magnified (right). Scale bars, $2 \mu \mathrm{m}$. B, Quantification of the relative fluorescence levels of INA-1::GFP between the proximal ends and internal region. The data are presented as box-blot graph with median (thick line within the box) and interquartile range (edge of box). A white circle indicates an outlier. The numbers $(n)$ of axons examined are shown below. The difference between FE(INA-1) end for nonaxotomized ( $0 \mathrm{~h})$ and axotomized (6 h) axons was tested for statistical significance with Mann-Whitney test. ${ }^{*} p<0.05$.

2010), whereas in the axon regeneration pathway, MLK-1 Ser355 phosphorylation is catalyzed by the PKC homolog TPA-1 (Pastuhov et al., 2012). Therefore, two different kinases, MAX-2 and TPA-1, can activate MLK-1 by phosphorylating the same Ser-355 site. Do these kinases function redundantly or independently? We have demonstrated previously that max-2-null mutants, unlike animals harboring mutations in $k g b-1$, mek-1, or $m l k-1$, remained partially resistant to heavy metal stress (Fujiki et al., 2010). Furthermore, the max-2 mutation caused a smaller decrease in KGB-1 activity than the $m l k-1$ mutation. These observations raised the possibility that another kinase may function redundantly with MAX-2 in transducing the heavy metal stress signal to MLK-1. In this study, we show that combining the tpa-1 mutation with the max-2 mutation resulted in greater sensitivity to heavy metal stress and significantly lower KGB-1 activity. Therefore, TPA-1 functions redundantly with MAX-2 in the heavy metal stress response. TPA-1 is necessary for axon regeneration of D-type motor neurons in the young adult stage, but not in the L4 stage (Pastuhov et al., 2012). Given that MLK-1 is required for axon regeneration in both the L4 and adult stages, we hypothesized that MAX-2 may activate MLK-1 mainly in the L4 stage to promote axon regeneration, and indeed we observed this to be the case.

Ste20-like protein kinases are regulated by small GTPases (Dan et al., 2001). These GTPases are active when bound to GTP and inactive after hydrolysis of the bound GTP to GDP. One

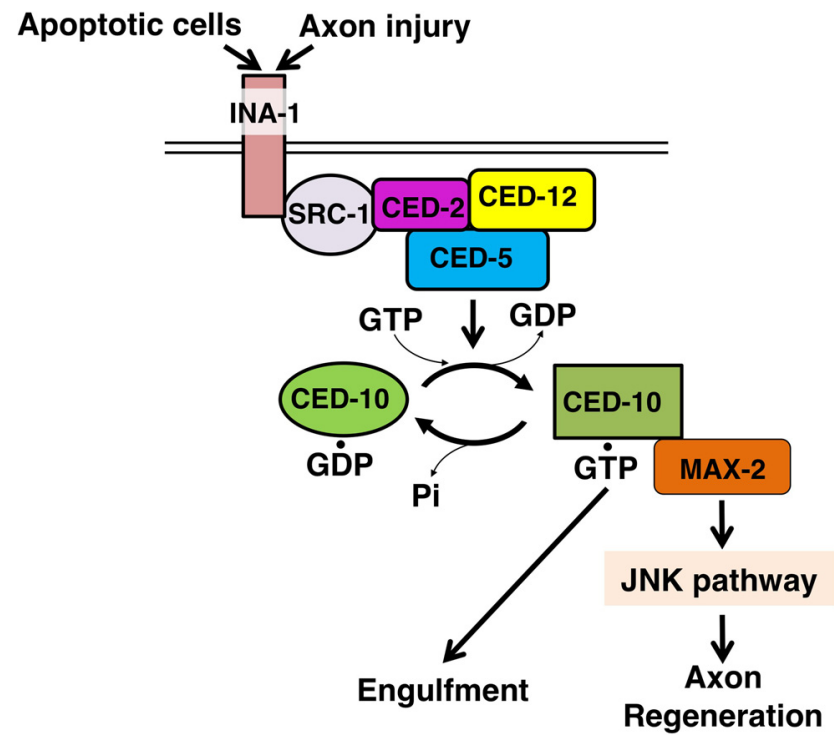

Figure 8. Schematic model for the regulation of axon regeneration by INA-1-CED-10-JNK signaling pathway.

family of Ste20-like kinases, PAK, has been shown to bind the GTP-bound form of the Cdc42/Rac family of GTPases through a CRIB domain found in PAK kinases (Bagrodia and Cerione, 1999). The PAK family member MAX-2 contains a CRIB motif in its $\mathrm{N}$-terminal domain and is regulated in the stress response pathway by MIG-2, a member of the Rac family of small GTPases (Fujiki et al., 2010). Conversely, in the axon regeneration pathway, MAX-2 is regulated by another Rac-type small GTPase, CED-10. The finding that MAX-2 interacted with the GTPbound form of CED-10, but not with the GDP-bound form, suggests that CED-10 may be involved in transmitting axon injury signals to MAX-2. This model is further supported by genetic analysis showing that the defect in axon regeneration observed in ced-10 mutants was not enhanced by the max- 2 mutation, but was suppressed by overexpression of the max-2 gene. Therefore, CED-10 and MAX-2 appear to act in the same pathway and function to promote axon regeneration by activating the KGB-1-JNK pathway (Fig. 8). Previous studies have revealed that CED-10 is required for the UNC-40/DCC-dependent developmental axon attraction and outgrowth, as well as the ventral guidance of regenerating adult axons, of AVM neurons (Gitai et al., 2003; Gabel et al., 2008). However, they are distinct processes because the unc-40 mutation has no effect on axon regeneration in D-type motor neurons (Nix et al., 2014).

In C. elegans, CED-10 is involved in the engulfment of apoptotic cells (Hsu and $\mathrm{Wu}, 2010$ ). The intracellular signaling proteins CED-2, CED-5, and CED-12 function as a GEF to activate CED-10 (Gumienny et al., 2001; Wu et al., 2001). The integrin $\alpha$-subunit, INA-1, recognizes apoptotic cells and mediates signaling through the CED-2-CED-5-CED-12 complex in the engulfing cells to promote cell corpse removal. Furthermore, the nonreceptor tyrosine kinase SRC-1 provides a link between INA-1 and the downstream signaling module CED-2-CED-5CED-12, leading to CED-10 activation (Hsu and $\mathrm{Wu}, 2010)$. In this study, we demonstrate that these intracellular signaling components also function upstream of MAX-2 in the axon regeneration pathway. Although the max-2 mutation also affected the engulfment of apoptotic cells, MAX-2 and CED-10 function in parallel pathways for cell corpse engulfment. Therefore, CED-10/ Rac-GTPase activates two separate signaling pathways, one that 
leads to axon regeneration and involves the JNK pathway and another that leads to the engulfment of apoptotic cells, but does not involve the JNK pathway (Fig. 8).

More recently, Nichols et al. (2016) demonstrated that the apoptotic machinery, including CED-2-CED-5-CED-12 and CED-10, regulates PLM axon degeneration. Therefore, the core molecular machinery used for the engulfment of apoptotic cells regulates both axon regeneration and degeneration. In the process of axon degeneration, the transmembrane receptor CED-1 functions non-cell autonomously in the surrounding hypodermis, which acts as the engulfing tissue for the severed axon. Conversely, CED-1 does not participate in axon regeneration, although INA-1 is involved in this process. INA-1 recognizes apoptotic cells through its extracellular domain and mediates signaling via its intracellular domain to promote apoptotic cell internalization (Hsu and Wu, 2010). Apoptotic cells display "eat me" signals, consisting primarily of phosphatidylserine (PS) on the outer leaflet of the plasma membrane that are recognized by engulfment receptors (Segawa and Nagata, 2015). Mammalian integrins can bind to externalized PS on apoptotic cells indirectly via bridging molecules such as the secreted MFG-E8 (Hanayama et al., 2002; Akakura et al., 2004). However, C. elegans does not appear to have an MFG-E8 homolog and it remains to be determined whether INA-1 recognizes externalized PS on the surface of apoptotic cells. Previous studies have identified the C. elegans secreted, transthyretin-like protein TTR-52 as a bridging molecule between PS on the surface of the apoptotic cell and the CED-1 receptor on the membrane of the engulfing cell (Wang et al., 2010). A recent study indicated that PS is exposed by axon severing and promotes axonal fusion in PLM neuron through a TTR-52-CED-1-dependent signaling pathway (Neumann et al., 2015). Our results suggest that the INA-1-mediated signaling pathway regulating the engulfment of apoptotic cells has been evolutionarily coopted for the regulation of axon regeneration. These findings raise the possibility that the externalized PS generated by axon severing is also recognized by INA- 1 indirectly via a bridging molecule to activate the CED-2-CED-5-CED-12 pathway. In this model, axonal injury induces the presentation of PS on the surface of the vesicles generated from the distal fragment of the severed axon. INA-1 may then recognize PS via a bridging molecule and activate the CED-2-CED-5-CED-12 pathway. To verify this possibility, it would be necessary to identify the nature of the signal that promotes axon regeneration and identify which cells generate the signal.

\section{References}

Akakura S, Singh S, Spataro M, Akakura R, Kim JI, Albert ML, Birge RB (2004) The opsonin MFG-E8 is a ligand for the alphavbeta5 integrin and triggers DOCK180-dependent Racl activation for the phagocytosis of apoptotic cells. Exp Cell Res 292:403-416. CrossRef Medline

Arimoto M, Koushika SP, Choudhary BC, Li C, Matsumoto K, Hisamoto N (2011) The Caenorhabditis elegans JIP3 protein UNC-16 functions as an adaptor to link kinesin-1 with cytoplasmic dynein. J Neurosci 31:2216-2224. CrossRef Medline

Bagrodia S, Cerione RA (1999) Pak to the future. Trends Cell Biol 9:350355. CrossRef Medline

Baum PD, Garriga G (1997) Neuronal migrations and axon fasciculation are disrupted in ina-1 integrin mutants. Neuron 19:51-62. CrossRef Medline

Brenner S (1974) The genetics of Caenorhabditis elegans. Genetics 77:71-94. Medline

Brugnera E, Haney L, Grimsley C, Lu M, Walk SF, Tosello-Trampont AC, Macara IG, Madhani H, Fink GR, Ravichandran KS (2002) Unconventional Rac-GEF activity is mediated through the Dock180-ELMO complex. Nat Cell Biol 4:574-582. Medline
Case LC, Tessier-Lavigne M (2005) Regeneration of the adult central nervous system. Curr Biol 15:R749-R753. Medline

Chen L, Wang Z, Ghosh-Roy A, Hubert T, Yan D, O’Rourke S, Bowerman B, Wu Z, Jin Y, Chisholm AD (2011) Axon regeneration pathways identified by systematic genetic screening in C. elegans. Neuron 71:1043-1057. CrossRef Medline

Chen ZL, Yu WM, Strickland S (2007) Peripheral regeneration. Annu Rev Neurosci 30:209-233. CrossRef Medline

Dan I, Watanabe NM, Kusumi A (2001) The Ste20 group kinases as regulators of MAP kinase cascades. Trends Cell Biol 11:220-230. CrossRef Medline

English J, Pearson G, Wilsbacher J, Swantek J, Karandikar M, Xu S, Cobb MH (1999) New insights into the control of MAP kinase pathways. Exp Cell Res 253:255-270. CrossRef Medline

Fujiki K, Mizuno T, Hisamoto N, Matsumoto K (2010) The Caenorhabditis elegans Ste20-related kinase and Rac-type small GTPase regulate the c-Jun $\mathrm{N}$-terminal kinase signaling pathway mediating the stress response. Mol Cell Biol 30:995-1003. CrossRef Medline

Gabel CV, Antoine F, Chuang CF, Samuel AD, Chang C (2008) Distinct cellular and molecular mechanisms mediate initial axon development and adult-stage axon regeneration in C. elegans. Development 135: 1129-1136. CrossRef Medline

Gitai Z, Yu TW, Lundquist EA, Tessier-Lavigne M, Bargmann CI (2003) The netrin receptor UNC-40/DCC stimulates axon attraction and outgrowth through Enabled and, in parallel, Rac and UNC-115/AbLIM. Neuron 37:53-65. CrossRef Medline

Gumienny TL, Brugnera E, Tosello-Trampont AC, Kinchen JM, Haney LB, Nishiwaki K, Walk SF, Nemergut ME, Macara IG, Francis R, Schedl T, Qin Y, Van Aelst L, Hengartner MO, Ravichandran KS (2001) CED-12/ ELMO, a novel member of the CrkII/Dock180/Rac pathway, is required for phagocytosis and cell migration. Cell 107:27-41. CrossRef Medline

Hammarlund M, Nix P, Hauth L, Jorgensen EM, Bastiani M (2009) Axon regeneration requires a conserved MAP kinase pathway. Science 323: 802-806. CrossRef Medline

Hanayama R, Tanaka M, Miwa K, Shinohara A, Iwamatsu A, Nagata S (2002) Identification of a factor that links apoptotic cells to phagocytes. Nature 417:182-187. CrossRef Medline

Hsu TY, Wu YC (2010) Engulfment of apoptotic cells in C. elegans is mediated by integrin alpha/SRC signaling. Curr Biol 20:477-486. CrossRef Medline

Ichijo H, Nishida E, Irie K, ten Dijke P, Saitoh M, Moriguchi T, Takagi M, Matsumoto K, Miyazono K, Gotoh Y (1997) Induction of apoptosis by ASK1, a mammalian MAPKKK that activates SAPK/JNK and p38 signaling pathways. Science 275:90-94. CrossRef Medline

James P, Halladay J, Craig EA (1996) Genomic libraries and a host strain designed for highly efficient two-hybrid selection in yeast. Genetics 144: 1425-1436. Medline

Kawasaki M, Hisamoto N, Iino Y, Yamamoto M, Ninomiya-Tsuji J, Matsumoto K (1999) A Caenorhabditis elegans JNK signal transduction pathway regulates coordinated movement via type-D GABAergic motor neurons. EMBO J 18:3604-3615. CrossRef Medline

Li C, Hisamoto N, Nix P, Kanao S, Mizuno T, Bastiani M, Matsumoto K (2012) The growth factor SVH-1 regulates axon regeneration in C. elegans via the JNK-MAPK cascade. Nat Neurosci 15:551-557. CrossRef Medline

Li C, Hisamoto N, Matsumoto K (2015) Axon regeneration Is regulated by Ets-C/EBP transcription complexes generated by activation of the cAMP/ $\mathrm{Ca} 2{ }^{+}$signaling pathways. PLoS Genet. 11:e1005603. CrossRef Medline

Lucanic M, Kiley M, Ashcroft N, L'etoile N, Cheng HJ (2006) The Caenorhabditis elegans $\mathrm{P} 21$-activated kinases are differentially required for UNC-6/netrin-mediated commissural motor axon guidance. Development 133:4549-4559. CrossRef Medline

Mello CC, Kramer JM, Stinchcomb D, Ambros V (1991) Efficient gene transfer in C.elegans: extrachromosomal maintenance and integration of transforming sequences. EMBO J 10:3959-3970. Medline

Mizuno T, Hisamoto N, Terada T, Kondo T, Adachi M, Nishida E, Kim DH, Ausubel FM, Matsumoto K (2004) The Caenorhabditis elegans MAPK phosphatase VHP-1 mediates a novel JNK-like signaling pathway in stress response. EMBO J 23:2226-2234. CrossRef Medline

Mizuno T, Fujiki K, Sasakawa A, Hisamoto N, Matsumoto K (2008) Role of the Caenorhabditis elegans Shc adaptor protein in the c-Jun N-terminal kinase signaling pathway. Mol Cell Biol 28:7041-7049. CrossRef Medline 
Neumann B, Coakley S, Giordano-Santini R, Linton C, Lee ES, Nakagawa A, Xue D, Hilliard MA (2015) EFF-1-mediated regenerative axonal fusion requires components of the apoptotic pathway. Nature 517:219-222. CrossRef Medline

Nichols AL, Meelkop E, Linton C, Giordano-Santini R, Sullivan RK, Donato A, Nolan C, Hall DH, Xue D, Neumann B, Hilliard MA (2016) The apoptotic engulfment machinery regulates axonal degeneration in C. elegans neurons. Cell Rep 14:1673-1683. CrossRef Medline

Ninomiya-Tsuji J, Kishimoto K, Hiyama A, Inoue J, Cao Z, Matsumoto K (1999) The kinase TAK1 can activate the NIK-I $\kappa \mathrm{B}$ as well as the MAP kinase cascade in the IL-1 signalling pathway. Nature 398:252-256. CrossRef Medline

Nix P, Hisamoto N, Matsumoto K, Bastiani M (2011) Axon regeneration requires coordinate activation of $\mathrm{p} 38$ and JNK-MAPK pathways. Proc Natl Acad Sci U S A 108:10738-10743. CrossRef Medline

Nix P, Hammarlund M, Hauth L, Lachnit M, Jorgensen EM, Bastiani M (2014) Axon regeneration genes identified by RNAi screening in C. elegans. J Neurosci 34:629-645. CrossRef Medline

Pastuhov SI, Fujiki K, Nix P, Kanao S, Bastiani M, Matsumoto K, Hisamoto N (2012) Endocannabinoid-Go $\alpha$ signalling inhibits axon regeneration in Caenorhabditis elegans by antagonizing Gq $\alpha$-PKC-JNK signalling. Nat Commun 3:1136. CrossRef Medline

Reddien PW, Horvitz HR (2000) CED-2/CrkII and CED-10/Rac control phagocytosis and cell migration in Caenorhabditis elegans. Nat Cell Biol 2:131-136. CrossRef Medline

Reddien PW, Horvitz HR (2004) The engulfment process of programmed cell death in Caenorhabditis elegans. Annu Rev Cell Dev Biol 20:193-221. CrossRef Medline
Segawa K, Nagata S (2015) An apoptotic "Eat Me" signal: phosphatidylserine exposure. Trends Cell Biol 25:639-650. CrossRef Medline

Spencer WC, Zeller G, Watson JD, Henz SR, Watkins KL, McWhirter RD, Petersen S, Sreedharan VT, Widmer C, Jo J, Reinke V, Petrella L, Strome S, Von Stetina SE, Katz M, Shaham S, Rätsch G, Miller DM 3rd (2011) A spatial and temporal map of C. elegans gene expression. Genome Res 21:325-341. CrossRef Medline

Wang X, Li W, Zhao D, Liu B, Shi Y, Chen B, Yang H, Guo P, Geng X, Shang Z, Peden E, Kage-Nakadai E, Mitani S, Xue D (2010) Caenorhabditis elegans transthyretin-like protein TTR-52 mediates recognition of apoptotic cells by the CED-1 phagocyte receptor. Nat Cell Biol 12:655-664. CrossRef Medline

Wu YC, Horvitz HR (1998) C. elegans phagocytosis and cell-migration protein CED-5 is similar to human DOCK180. Nature 392:501-504. CrossRef Medline

Wu YC, Tsai MC, Cheng LC, Chou CJ, Weng NY (2001) C. elegans CED-12 acts in the conserved CrkII/DOCK180/Rac pathway to control cell migration and cell corpse engulfment. Dev Cell 1:491-502. CrossRef Medline

Yan D, Wu Z, Chisholm AD, Jin Y (2009) The DLK-1 kinase promotes mRNA stability and local translation in C. elegans synapses and axon regeneration. Cell 138:1005-1018. CrossRef Medline

Yanik MF, Cinar H, Cinar HN, Chisholm AD, Jin Y, Ben-Yakar A (2004) Neurosurgery: functional regeneration after laser axotomy. Nature 432: 822. CrossRef Medline

Zhou Z, Hartwieg E, Horvitz HR (2001) CED-1 is a transmembrane receptor that mediates cell corpse engulfment in C. elegans. Cell 104:43-56. CrossRef Medline 